\title{
Resistência de genótipos de batata ao pulgão
}

\author{
Fernando M. Lara'; ${ }^{1}$ Alexandre Corbo'; Liliane K. Figueira'; César P. Stein ${ }^{2}$
}

1UNESP, Depto. Fitossanidade, 14884-900 Jaboticabal-SP; E mail: fmlara@fcav.unesp.br; ${ }^{2}$ IAC, CPD de Fitossanidade/Entomologia, C. Postal 28, 13001-970 Campinas-SP; E mail: cpstein@iac.sp.gov.br

\section{RESUMO}

Avaliou-se a resistência (e antibiose) de genótipos de batata, comerciais e em fase de melhoramento, ao pulgão Myzus persicae, em ensaios efetuados com plantas em vasos, sem chance de escolha, em Jaboticabal (SP). Foram efetuados seis experimentos, utilizando-se um total de 16 genótipos, a saber: 'Achat', 'Apuã', 'Aracy', 'Aracy Ruiva', 'Bintje', 'Ibitu Açu', 'Itararé', 'N 140-201', 'NYL 235-4', '288.719-13', '288.764-26', '288.776-3', '288.776-6', '288.794-19', '288.801-6' e '288.814-7'. Em cada experimento foram utilizadas combinações variadas dos mesmos. Nos dois primeiros experimentos as plantas foram infestadas com 30 pulgões adultos por planta, distribuídos em três folhas, com três avaliações realizadas em semanas subseqüentes à infestação, contando-se o número de indivíduos por planta. O terceiro experimento foi conduzido aprisionando-se duas fêmeas adultas no interior de pequenas gaiolas fixadas na face abaxial dos folíolos, em número de dez por planta, avaliando-se a reprodução do pulgão após sete dias, em dois plantios. No quarto experimento efetuou-se a infestação da planta com 15 pulgões, avaliando-se o crescimento da população na planta toda durante três semanas consecutivas. No quinto experimento foi avaliada a descendência de uma única fêmea adulta por folíolo e no sexto experimento avaliou-se o peso dos pulgões aos sete dias de vida. Os tricomas glandulares presentes nos folíolos e a funcionalidade dos mesmos também foram avaliados. A cultivar 'Ibitu Açu' apresentou elevado grau de antibiose a $M$. persicae; os genótipos '288.776-3' e '288.794-19' também apresentaram esse tipo de resistência, em grau moderado; '288.719-13' e '288.764-26' foram resistentes ao pulgão, provavelmente devido à presença de tricomas glandulares funcionais, dos tipos A e B, em seus folíolos (antixenose); entre os mais suscetíveis destacaram-se 'Bintje' e '288.801-6'.

Palavras-chave: Solanum tuberosum, Myzus persicae, resistência de plantas, antixenose, antibiose.

\author{
ABSTRACT \\ Potato genotypes resistance to the green peach aphid Myzus \\ persicae
}

Potato genotypes and clones were evaluated for resistance (and antibiosis) to the green peach aphid Myzus persicae, in experiments carried out with potted plants using vases (no choice tests), in Jaboticabal, São Paulo State, Brazil. Sixteen genotypes were used in six experiments: 'Achat', 'Apuã', 'Aracy', 'Aracy Ruiva', 'Bintje', 'Ibitu Açu', 'Itararé', 'N 140-201', 'NYL 235-4', '288.719-13', '288.764-26', '288.776-3', '288.776-6', '288.794-19', '288.801-6' and '288.814-7'. In each experiment different combinations of these genotypes were used. In the first two experiments the plants were infested with 30 adults distributed in three leaves; after infestation three evaluations were done during the subsequent weeks. The third experiment was carried out arresting two adult females inside small cages fastened in the lower surface of the leaflets; the reproduction of the aphid was evaluated after seven days using two plantings. In the fourth experiment, 15 aphids were placed on each plant to evaluate the growth of the population, by counting the number of aphids/ plant in three subsequent weeks. In the fifth experiment the number of nymphs/female was evaluated, while in the sixth experiment the nymphs weight was evaluated at the seventh day of life. The density of glandular trichomes was measured on lower laminar surface and on the main vein of mature leaves. The functionality of the glandular trichomes was also evaluated. The commercial genotype Ibitu Açu presented a high degree of antibiosis to $M$. persicae; the genotypes 288.776-3 and 288.794-19 also presented this mechanism of resistance, in moderate degree; '288.719-13' and '288.764-26' were also resistant to the green peach aphid, probably due to the presence of functional glandular trichomes, types A and $\mathrm{B}$, in their leaflets (antixenosis). The commercial genotype Bintje and the clone 288.801-6 were the most susceptible.

Keywords: Solanum tuberosum, Myzus persicae, host plant resistance, atixenosis, antibiosis.

\section{(Recebido para publicação em 6 de setembro de 2003 e aceito em 17 de julho de 2004)}

$\mathrm{O}$ cultivo da batata nos trópicos é um dos que mais sofre com problemas fitossanitários decorrentes de ataques de pragas e doenças, onerando o custo de produção. Entre as pragas que freqüentemente atacam a cultura destacam-se os pulgões, que além de causarem danos diretos com a sucção da seiva, também causam danos indiretos com a transmissão de viroses. O pulgão Myzus persicae (Sulzer) (Hemiptera: Aphididae) é considerado uma das pragas mais importante dessa cultura pois, ao atingirem altas densidades podem causar um estresse hídrico nas plantas, resultando no murchamento e na redução da taxa de crescimento, redução no tamanho dos tubérculos e da folhagem das plantas (Petitt e Smilowitz, 1982). No entanto, para Derron e Goy (1995), importância maior deve ser atribuída à esse inseto pela sua alta capacidade de transmissão de viroses.

Embora se reconheça a importância do controle químico e cultural no manejo integrado dessa praga, a incorpo- ração de resistência ao inseto em cultivares comerciais é bastante desejável (Radcliffe, 1982). As fontes de resistência a pragas foram encontradas, inicialmente, em espécies selvagens de Solanum Linn. e estão relacionadas, principalmente, com a presença de glicoalcalóides em diferentes partes da planta e com a de tricomas glandulares nas folhas, nervuras e caules, que ao serem rompidos liberam exsudatos adesivos que agem mecanicamente, aprisionando os insetos e obstruindo o seu apa- 
rato bucal (Radcliffe e Lauer 1971).

Os tricomas glandulares também têm sido estudados em espécies como Solanum berthaultii, S. neocardenasii, S. polyadenium, S. tarijense e em híbridos interespecíficos de $S$. berthaultii x S. tarijense (Tingey e Yencho, 1994). Em híbridos de $S$. tuberosum x $S$. berthaultii, que apresentam tricomas glandulares tipos A e B, foi constatada a redução da população de afídeos em mais de $61 \%$ quando comparado com cultivares suscetíveis (Tingey et al., 1982; Xia e Tingey, 1986).

A ocorrência de estímulos antixenóticos ao pulgão $M$. persicae ficaram evidenciados quando clones selvagens de $S$. berthaultii, portadores de tricomas glandulares nas hastes e folhas, foram comparados com cultivares comerciais de $S$. tuberosum por Moraes e Vilela (1995). Os resultados demonstraram que os clones portadores dos dois tipos de tricomas glandulares foram os menos colonizados pelo pulgão $M$. persicae.

Em ensaios com chance de escolha, em condições de campo, Stein (1998) observou uma variação de 0,4 a 1,1 adulto áptero de $M$. persicae por folha, concluindo que as cultivares Aracy e Achat apresentaram resistência do tipo antixenose a $M$. persicae quando comparadas com as cultivares Itararé e Apuã e com os clones N 140-201 e NYL 2354. De forma semelhante, Lara et al. (1999) verificaram que o clone NYL 235-4 revelou-se suscetível a Macrosiphum euphorbiae sob infestações médias de 2,90 e 1,19 pulgões/planta e, ainda, que nesse clone ocorreram as maiores taxas de parasitismo por Aphidius ervi (15\%) e Diaretiella rapae (36\%).

O presente trabalho teve por objetivo avaliar a resistência a $M$. persicae em genótipos de batata, comerciais e em fase de melhoramento, e a ocorrência do tipo de resistência, antibiose, naqueles que revelaram aquela característica.

\section{MATERIAL E MÉTODOS}

Foram utilizadas cultivares comerciais de batata, fornecidas pelo IAC, e genótipos em fase de melhoramento fornecidos pela Universidade de Cornell
(EUA) e pela Embrapa Hortaliças. Para cada ensaio, efetuou-se o plantio em vasos, manualmente, sendo o preparo do solo, adubações e tratos culturais realizados segundo as recomendações normais para a cultura, inclusive a aplicação de fungicidas e bactericidas. Efetuaram-se também aplicações de deltametrina (Decis $50 \mathrm{SC}$ ), em doses variando de 0,3 a $0,4 \mathrm{ml} / \mathrm{L}$, objetivandose evitar a presença de inimigos naturais. A criação de $M$. persicae foi mantida em hospedeiros como pimentão, rabanete selvagem e Datura sp.

Foram efetuados seis experimentos, utilizando-se um total de 16 genótipos: 'Achat', 'Apuã', 'Aracy', 'Aracy Ruiva', 'Bintje', 'Ibitu Açu', 'Itararé' 'N 140-201', 'NYL 235-4', '288.719-13', '288.764-26', '288.776-3', '288.776-6', '288.794-19', ‘288.801-6’ e '288.8147'. Em cada experimento foram utilizadas combinações variadas dos mesmos.

Os experimentos I e II, foram realizados no ano de 2000, no campo, sem chance de escolha, com os vasos no interior de telados, individualizados em gaiolas circulares de $20 \mathrm{~cm}$ de diâmetro e $60 \mathrm{~cm}$ de altura, cobertas com tecido "voil", utilizando-se os genótipos relacionados nas Tabelas 1 e 2, respectivamente. Eles foram mantidos em cinco telados, cada um contendo todos os genótipos, num delineamento estatístico de blocos ao acaso. As plantas foram infestadas com 30 pulgões ápteros, distribuídos em três folhas, e o número de indivíduos por planta foi contado em três avaliações realizadas aos 48, 55 e 62 dias após o plantio (DAP) no experimento I e aos 23, 30 e 37 DAP no II.

Em 2001, foram realizados os experimentos III e IV em condições de telado, utilizando-se os genótipos relacionados na Tabela 3 (exceto o clone '288.719-13') em vasos, com plantas também individualizadas em gaiolas. No experimento III (repetido duas vezes, ensaios 1 e 2), as infestações foram efetuadas em plantas com idade entre 25 a 46 dias após o plantio, acondicionando-se duas fêmeas adultas em pequenas gaiolas plásticas ( 25 × $25 \mathrm{~mm})$, com tampas teladas (13 mm de diâmetro por $3 \mathrm{~mm}$ de altura), fixadas na face inferior das folhas. Foram colocadas dez gaiolas por planta, obtendo-se dados de três infestações subseqüentes, num total de 52 e 46 repetições por tratamento para os ensaios 1 e 2, respectivamente, num delineamento estatístico inteiramente casualizado. Uma semana após a infestação, contou-se o número de descendentes nas colônias e calculou-se o número médio deles por fêmea. No experimento IV, o crescimento populacional foi avaliado em todos os genótipos infestando-se as plantas, individualizadas em vasos, com 15 pulgões, num delineamento de blocos ao acaso, em número de 6 . As avaliações foram realizadas aos 7, 14 e 21 dias após a infestação e os resultados obtidos foram utilizados para calcular o número de vezes que a população cresceu naqueles intervalos.

Em 2002 realizaram-se os experimentos V e VI com os mesmos genótipos do experimento III, acrescidos do clone 288.719-13 (Tabela 3). O primeiro foi conduzido de forma semelhante ao experimento III. As pequenas gaiolas plásticas foram fixadas em folíolos de plantas com 20 dias de idade e cada uma recebeu apenas uma fêmea adulta, proveniente de colônia mantida em pimentão. A avaliação para a obtenção do número de descendentes obtidos por fêmea foi realizada 7 dias após a infestação. O delineamento estatístico utilizado foi o inteiramente casualizado com 7 tratamentos (genótipos) e 35 repetições.

Para avaliar o efeito dos genótipos sobre o desenvolvimento (peso) do inseto, foi realizado o experimento VI em câmara climatizada $\left(25 \pm 2^{\circ} \mathrm{C}, 80 \pm 5 \%\right.$ UR), utilizando-se os mesmos sete genótipos do experimento $\mathrm{V}$, com 6 repetições, em delineamento inteiramente casualizado. Discos de folhas $(30 \mathrm{~mm}$ de diâmetro) de plantas com 20 dias de idade foram colocados em pequenas placas de Petri, sobre uma camada de aproximadamente $3 \mathrm{~mm}$ de agar $(10 \mathrm{~g} /$ $1200 \mathrm{ml}$ de água) ainda morno, com o objetivo de fixar melhor o disco e impedir a colonização dos pulgões na face inferior do mesmo. Em cada disco foram colocadas 10 ninfas recém emergidas, obtidas de fêmeas provenientes de plantas de pimentão e previamente mantidas em discos semelhantes, de cada genótipo, para obtenção da prole 
com mesma idade. Após o sétimo dia, as ninfas foram retiradas e pesadas, obtendo-se em seguida o peso médio/ pulgão (Tabela 3).

Em 2000, com exceção da 'Bintje' e do clone 288.776-6 (Tabela 4), os genótipos foram avaliados quanto à presença de tricomas dos tipos A e B (experimento VII). Foram utilizados folíolos totalmente desenvolvidos, obtidos do terço médio das plantas. Com o auxílio de um microscópio estereoscópico (40x) foram efetuadas contagens dos tricomas existentes em duas áreas de $1 \mathrm{~mm}^{2}$ do limbo foliar (página inferior), ao lado da nervura principal, e também nesta. Foram realizadas seis repetições (DIC). A funcionalidade ou não dos tricomas glandulares tipo $\mathrm{A}$ e tipo $\mathrm{B}$, quanto à produção de adesivo, foi verificada através de observação da movimentação de pulgões e da ocorrência de adesivo em seus tarsos e peças bucais.

\section{RESULTADOS E DISCUSSÃO}

Pelos resultados do experimento I (Tabela 1), verifica-se que, nas três datas de avaliação, a cultivar Bintje foi a que mais favoreceu o desenvolvimento do pulgão; os demais genótipos não apresentaram diferenças significativas entre si e houve uma nítida tendência da 'Ibitu Açu' em manter uma baixa população. As cultivares Aracy, Itararé e Apuã mostraram comportamento semelhante ao observado por Stein (1998), mantendo uma posição intermediária quando comparadas com os genótipos N 140-201, NYL 235-4 e Achat. Na Tabela 2 (experimento II), observa-se que a população do pulgão desenvolveu-se bem mais que no ensaio anterior. Os genótipos 288.764-26 e 288.719-13 revelaram-se os mais resistentes ao pulgão, com médias das três avaliações de 46,67 e 56,13 pulgões/planta, respectivamente. Neste caso a expressão da resistência provavelmente esteja relacionada à funcionalidade dos tricomas glandulares tipos A e B presentes nesses clones, conforme resultados do experimento VII (Tabela 4), conferindo uma linha de defesa contra o ataque do pulgão, imobilizando suas patas, aparelho bucal, causando-lhes a morte, con-

Tabela 1. Número de M. persicae/planta encontrado em genótipos de batata, aos 48, 55 e 62 dias após o plantio. Experimento I. Jaboticabal, UNESP, 2000. ${ }^{1}$

\begin{tabular}{lcrcc}
\hline \multirow{2}{*}{ Genótipos } & \multicolumn{4}{c}{ Avaliações } \\
\cline { 2 - 5 } & $\mathbf{4 8}$ dias & $\mathbf{5 5}$ dias & $\mathbf{6 2}$ dias & Média \\
\hline Apuã & 51,40 & $88,00 \mathrm{~b}$ & $105,60 \mathrm{~b}$ & 81,66 \\
Aracy & 44,60 & $163,60 \mathrm{~b}$ & $152,20 \mathrm{~b}$ & 120,13 \\
Aracy Ruiva & 53,00 & $115,80 \mathrm{~b}$ & $203,80 \mathrm{~b}$ & 124,20 \\
Bintje & 122,20 & $411,80 \mathrm{a}$ & $776,20 \mathrm{a}$ & 436,73 \\
Ibitu Açu & 72,40 & $80,60 \mathrm{~b}$ & $14,80 \mathrm{~b}$ & 55,93 \\
Itararé & 71,20 & $138,80 \mathrm{~b}$ & $395,00 \mathrm{ab}$ & 201,67 \\
288.776-6 & 56,00 & $183,60 \mathrm{~b}$ & $245,20 \mathrm{~b}$ & 161,60 \\
\hline F & 1,37 ns & 4,02 * & $5,75^{*}$ & 1,93 ns \\
\hline C.V. (\%) & 16,32 & 13,63 & 23,43 & 16,30 \\
\hline
\end{tabular}

${ }^{1}$ Dados originais. Para análise estatística foram transformados em $\ln (x+5) ; *$ Significativo

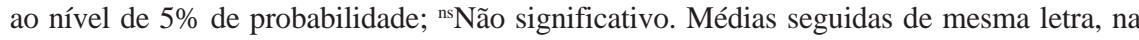
mesma coluna, não diferem entre si (Tukey, 5\%).

Tabela 2. Número de $M$. persicae/planta encontrado em genótipos de batata, aos 23, 30 e 37 dias após o plantio. Experimento II. Jaboticabal, UNESP, 2000. ${ }^{1}$

\begin{tabular}{lcccc}
\hline \multirow{2}{*}{ Genótipos } & $\mathbf{5}$ & \multicolumn{4}{c}{ Avaliações } & (dias) \\
\cline { 2 - 5 } & $\mathbf{2 3}$ & $\mathbf{3 0}$ & $\mathbf{3 7}$ & Médias \\
\hline Achat & $87,20 \mathrm{ab}$ & $237,40 \mathrm{ab}$ & $321,60 \mathrm{ab}$ & $215,40 \mathrm{abc}$ \\
Apuã & $84,00 \mathrm{ab}$ & $173,20 \mathrm{ab}$ & $246,20 \mathrm{ab}$ & $167,80 \mathrm{bcd}$ \\
Aracy & $97,60 \mathrm{ab}$ & $250,20 \mathrm{ab}$ & $197,20 \mathrm{ab}$ & $181,67 \mathrm{abcd}$ \\
Aracy Ruiva & $81,00 \mathrm{ab}$ & $131,40 \mathrm{ab}$ & $449,20 \mathrm{ab}$ & $220,53 \mathrm{abc}$ \\
Ibitu Açu & $56,20 \mathrm{ab}$ & $139,40 \mathrm{ab}$ & $199,00 \mathrm{ab}$ & $131,53 \mathrm{bcd}$ \\
Itararé & $47,60 \mathrm{ab}$ & $98,20 \mathrm{ab}$ & $156,40 \mathrm{ab}$ & $100,73 \mathrm{bcd}$ \\
N 140-201 & $121,40 \mathrm{a}$ & $247,20 \mathrm{ab}$ & $361,60 \mathrm{ab}$ & $243,40 \mathrm{ab}$ \\
NYL 235-4 & $85,60 \mathrm{ab}$ & $185,00 \mathrm{ab}$ & $272,60 \mathrm{ab}$ & $181,27 \mathrm{abcd}$ \\
$288.719-13$ & $27,20 \mathrm{~b}$ & $51,00 \mathrm{~b}$ & $90,20 \mathrm{~b}$ & $56,13 \mathrm{~cd}$ \\
$288.764-26$ & $25,00 \mathrm{~b}$ & $36,20 \mathrm{~b}$ & $78,80 \mathrm{~b}$ & $46,67 \quad \mathrm{~d}$ \\
$288.776-3$ & $42,60 \mathrm{ab}$ & $32,00 \mathrm{~b}$ & $172,20 \mathrm{ab}$ & $82,27 \mathrm{bcd}$ \\
$288.794-19$ & $80,60 \mathrm{ab}$ & $178,60 \mathrm{ab}$ & $226,80 \mathrm{ab}$ & $162,00 \mathrm{bcd}$ \\
$288.801-6$ & $79,60 \mathrm{ab}$ & $367,40 \mathrm{a}$ & $565,80 \mathrm{a}$ & $337,60 \mathrm{a}$ \\
$288.814-7$ & $47,80 \mathrm{ab}$ & $114,60 \mathrm{ab}$ & $112,00 \mathrm{~b}$ & $91,47 \mathrm{bcd}$ \\
\hline F & $3,65 *$ & $7,73 *$ & $3,81{ }^{*}$ & 8,70 * \\
\hline C.V \% & 12,48 & 12,25 & 16,63 & 9,53 \\
\hline
\end{tabular}

${ }^{1}$ Dados originais. Para análise estatística foram transformados em $\ln (\mathrm{x}+5)$; *Significativo ao nível de $5 \%$ de probabilidade. Médias seguidas de mesma letra, na mesma coluna, não diferem entre si (Tukey, 5\%).

forme constatado pelos autores deste trabalho e por outros autores como Tingey et al. (1982) e Jonjin et al. (1999), com outros genótipos portadores daqueles tricomas. Ainda pela Tabela 2, sem diferir significativamente desses genótipos, seguiram-se '288.7763', '288.814-7', 'Itararé', 'Ibitu Açu', '288.794-19' e 'Apuã', com médias variando de 82,27 a 167,80 pulgões/planta, demonstrando possuírem resistência moderada ao pulgão, porém com uma progênie duas ou mais vezes superiores que as dos clones resistentes. Nota-se, também, que o genótipo 288.801-6 revelou-se o mais suscetível, com 337,60 pulgões/planta e que não diferiu significativamente dos clones avançados $\mathrm{N}$ 140-201 e NYL 235-4. Estes não diferiram de 'Achat', 'Aracy', 'Itararé' e 'Apuã', como também foi observado por Stein (1998).

O experimento III, referente ao confinamento em gaiolas plásticas (ensaios 1 e 2, Tabela 3), revelou a formação de 3 grupos de genótipos em relação à suscetibilidade ao pulgão. Notase que a cultivar Bintje e o clone 
Tabela 3. Número médio de descendentes produzido por fêmea durante sete dias; crescimento populacional (em nº de vezes) de M. persicae, a partir de 15 fêmeas; número de pulgões produzidos/fêmea durante sete dias e peso do pulgão com sete dias de idade confinados em discos de folhas, em genótipos de batata. Experimentos III, IV, V e VI. Jaboticabal, UNESP, 2001/02.1

\begin{tabular}{|c|c|c|c|c|c|c|c|}
\hline \multirow[b]{2}{*}{ Genótipos } & \multicolumn{2}{|c|}{$\mathrm{N}^{\circ}$ de pulgões } & \multicolumn{3}{|c|}{ Crescimento populacional } & \multirow{2}{*}{$\begin{array}{c}\mathrm{N}^{\circ} \mathrm{de} \\
\text { pulgões/fêmea }\end{array}$} & \multirow{2}{*}{$\begin{array}{l}\text { Peso de um } \\
\text { pulgão }(\mathrm{mg}\end{array}$} \\
\hline & $\begin{array}{c}\text { Ensaio } 1 \\
(n=52)\end{array}$ & $\begin{array}{c}\text { Ensaio } 2 \\
(n=46)\end{array}$ & 07 dias & 14 dias & 21 dias & & \\
\hline Bintje & 13,46 a & $11,39 \mathrm{~b}$ & $3,33 a$ & 6,67 & $26,59 a b$ & $12,66 \mathrm{a}$ & $0,375 \mathrm{~b}$ \\
\hline Ibitu Açu & $3,21 \mathrm{c}$ & 3,39 e & $1,44 \mathrm{a}$ & 4,15 & $14,31 \mathrm{~b}$ & $3,74 \mathrm{~d}$ & $0,417 a b$ \\
\hline $288.719-13$ & - & - & - & - & - & $7,49 \mathrm{bc}$ & $0,372 \mathrm{~b}$ \\
\hline $288.776-3$ & $9,98 \mathrm{~b}$ & $5,39 d$ & $2,80 \mathrm{a}$ & 4,88 & $25,19 a b$ & $7,17 \mathrm{~cd}$ & $0,468 a b$ \\
\hline $288.776-6$ & 15,58 a & 15,50 a & $1,93 a$ & 4,93 & 37,46 a & $10,20 \mathrm{ab}$ & $0,477 \mathrm{ab}$ \\
\hline $288.794-19$ & $9,64 \mathrm{~b}$ & $9,28 \mathrm{bc}$ & 2,57 a & 5,26 & - & $8,06 \mathrm{bc}$ & $0,505 \mathrm{a}$ \\
\hline 288.814-7 & $7,60 \mathrm{~b}$ & $6,80 \mathrm{~cd}$ & $3,58 \mathrm{a}$ & 7,31 & $27,91 \mathrm{ab}$ & $12,71 \mathrm{a}$ & $0,485 a$ \\
\hline $\mathrm{F}$ & 35,51 * & 39,22 * & 2,67 * & $1,14^{\mathrm{ns}}$ & 4,29 * & 16,17 * & $5,11^{*}$ \\
\hline$\overline{C . V \%}$ & 15,66 & 14,81 & 7,48 & 9,33 & 9,71 & 14,37 & 13,33 \\
\hline
\end{tabular}

${ }^{1}$ Dados originais. Para análise estatística foram transformados em $\ln (\mathrm{x}+5) \cdot \mathrm{n}=$ número de repetições; *Significativo ao nível de $5 \%$ de

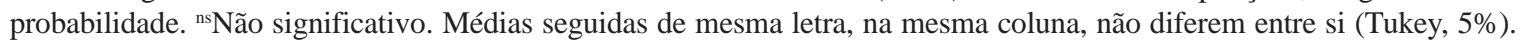

Tabela 4. Número e atividade de tricomas tipo A e B encontrados no limbo e nervura de genótipos de batata. Experimento VII. Jaboticabal, UNESP, 2000. ${ }^{1}$

\begin{tabular}{|c|c|c|c|c|c|c|}
\hline \multirow{2}{*}{ Genótipos } & \multicolumn{3}{|c|}{ Número de tricomas tipo $\mathrm{A}$} & \multicolumn{3}{|c|}{ Número de tricomas tipo $B$} \\
\hline & Limbo/mm ${ }^{2}$ & nervura/mm ${ }^{2}$ & Ativ. $^{2}$ & limbo/mm ${ }^{2}$ & nervura/mm ${ }^{2}$ & Ativ. $^{2}$ \\
\hline Achat & $0,4 \mathrm{~cd}$ & 1,2 & NF & $0,0 \mathrm{c}$ & $0,0 \mathrm{c}$ & - \\
\hline Apuã & $5,1 a b$ & 2,0 & NF & $0,0 \mathrm{c}$ & $0,0 \mathrm{c}$ & - \\
\hline Aracy & $2,3 \mathrm{bcd}$ & 0,4 & $\mathrm{NF}$ & $0,0 \mathrm{c}$ & $0,0 \mathrm{c}$ & - \\
\hline Aracy Ruiva & 6,3 a & 1,2 & $\mathrm{NF}$ & $0,0 \mathrm{c}$ & $0,0 \mathrm{c}$ & - \\
\hline Ibitu Açu & $3,1 \mathrm{abc}$ & 0,0 & $\mathrm{NF}$ & $0,0 \mathrm{c}$ & $0,0 \mathrm{c}$ & - \\
\hline Itararé & $2,3 \mathrm{bcd}$ & 1,6 & $\mathrm{NF}$ & $0,0 \mathrm{c}$ & $0,0 \mathrm{c}$ & - \\
\hline N 140-201 & $2,2 \mathrm{bcd}$ & 1,2 & $\mathrm{NF}$ & $0,0 \mathrm{c}$ & $0,4 \mathrm{bc}$ & $\mathrm{NF}$ \\
\hline NYL 235-4 & $2,3 \mathrm{bcd}$ & 0,6 & NF & $0,0 \mathrm{c}$ & $0,0 \mathrm{c}$ & - \\
\hline $288.719-13$ & $0,9 \mathrm{~cd}$ & 0,6 & $\mathrm{~F}$ & $5,9 \mathrm{~b}$ & $1,6 \mathrm{~b}$ & $\mathrm{~F}$ \\
\hline $288.764-26$ & $0,4 \mathrm{~cd}$ & 1,0 & $\mathrm{~F}$ & $7,6 \mathrm{a}$ & $7,0 \mathrm{a}$ & $\mathrm{F}$ \\
\hline $288.776-3$ & $0,6 \mathrm{~cd}$ & 0,4 & $\mathrm{NF}$ & $0,0 \mathrm{c}$ & $0,0 \mathrm{c}$ & - \\
\hline 288.794-19 & $0,7 \mathrm{~cd}$ & 0,6 & $\mathrm{NF}$ & $0,0 \mathrm{c}$ & $0,0 \mathrm{c}$ & - \\
\hline $288.801-6$ & $1,0 \mathrm{~cd}$ & 0,2 & $\mathrm{NF}$ & $0,0 \mathrm{c}$ & $0,0 \mathrm{c}$ & - \\
\hline 288.814-7 & $0,0 \mathrm{~d}$ & 0,0 & - & $0,0 \mathrm{c}$ & $0,0 \mathrm{c}$ & - \\
\hline $\mathrm{F}$ & 8,48 * & 1,51 ns & & 109,32 * & 38,51 * & \\
\hline C.V. (\%) & 9,70 & 9,40 & & 3,79 & 5,00 & \\
\hline
\end{tabular}

${ }^{1}$ Dados originais. Para análise estatística foram transformados em $\ln (\mathrm{x}+5) ;{ }^{*}$ Significativo

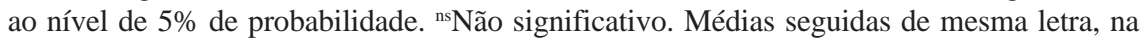
mesma coluna, não diferem entre si (Tukey, $5 \%$ ) ${ }^{2} \mathrm{~F}=$ funcional; $\mathrm{NF}=$ não funcional.

228.776-6 formaram o grupo suscetível ou seja, o que mais favoreceu a reprodução das fêmeas. Os genótipos 288.814-7, 288.776-3 e 288.794-19 apresentaram uma resistência moderada, enquanto a cultivar Ibitu Açu confirmou sua alta resistência ao desenvolvimento de $M$. persicae. Na observação dos dados do crescimento da população na planta toda, a partir de 15 pulgões (Tabela 3), nota-se diferença significativa entre os tratamentos apenas aos 21 dias após a infestação, com o genótipo
Ibitu Açu revelando a presença de alto grau de antibiose, tendo a população de pulgões, nesse genótipo, aumentado apenas 14 vezes, enquanto que em '288.776-6' o crescimento foi de mais de 37 vezes. Em '288.794-19' houve contaminação experimental e os dados foram eliminados, sendo reavaliado em novo ensaio no ano de 2002. Em '288.776-3' e '288.814-7' a população de pulgões cresceu 25 a 28 vezes, após os 21 dias, dados esses que sugerem grau médio de antibiose nesses genótipos.
No ensaio de 2002, referente à reprodução do pulgão (experimento $\mathrm{V}$ ), os dados confirmaram a resistência da cultivar Ibitu Açu (3,74 ninfas/fêmea). Esta cultivar foi a menos favorável ao desenvolvimento do inseto, seguida do clone 288.776-3 (7,17 ninfas/fêmea), enquanto o clone 288.814-7 apresentou o maior número de progênie (12,71). A cultivar Bintje revelou-se, mais uma vez, uma das mais favoráveis ao desenvolvimento do pulgão, com uma média de 12,66 ninfas/fêmea. Os menores pesos de pulgões foram observados em '288.719-13' e 'Bintje', enquanto os maiores ocorreram nos genótipos 288.794-19 e 288.814-7. No entanto, não se observou uma relação direta entre o peso e a descendência e/ou crescimento populacional do pulgão. Reinink e Dieleman (1989) creditaram a baixa correlação entre peso de duas espécies de afídeos (Macrosiphum euphorbiae e Uroleucon sonchi) e 90 genótipos diferentes de alface à especificidade de alguns componentes da resistência à cada espécie de pulgão estudada.

Diversos estudos têm demonstrado os efeitos negativos da presença de tricomas glandulares e de seus semioquímicos sobre diversas espécies de insetos pragas, revelando-se como causa da resistência aos mesmos (Lara, 1991). Neste trabalho pode-se constatar que os clones 288.719-13 e 288.76426 apresentaram resistência antixenótica ao pulgão $M$. persicae em decorrência da presença de tricomas glandulares dos 
tipos A e B funcionais em suas folhas sendo, portanto, um fator importante a ser considerado em um programa de melhoramento genético.

As diferenças observadas nos materiais quanto ao número de afídeos ainda pode estar associada a outros fatores não avaliados na presente pesquisa. Um deles poderia ser a diferença nutricional dos genótipos, uma vez que Kuroli et al. (1998), ao analisarem as folhas de 100 genótipos de batata durante 15 anos, observaram que os teores de carboidrato e de gordura apresentam correlação negativa com o número de afídeos (alto teor diminui o número de afídeos), ocorrendo, ao analisarem as folhas de 100 genótipos de batata durante 15 anos, o inverso com o conteúdo de proteína (alto teor induz um aumento de sua população). Os materiais estudados apresentaram diversos graus de resistência. A cultivar Ibitu Açu apresentou elevado grau de antibiose a $M$. persicae e os genótipos 288.776-3 e 288.794-19 apresentaram um grau moderado deste tipo de resistência, podendo ser incorporados em programas de melhoramento da batata objetivando reunir as qualidades organolépticas das cultivares comerciais com a resistência a afídeos. A cultivar Bintje e o clone 288.801-6 foram os que apresentaram os maiores graus de suscetibilidade ao ataque do pulgão $M$. persicae.

\section{AGRADECIMENTOS}

Os autores expressam seus agradecimentos ao CNPq e a FAPESP, pelas bolsas, e a Embrapa Hortaliças pelo fornecimento de sementes.

\section{LITERATURA CITADA}

DERRON, J.O.; GOY, G. Aphids colonizing potatoes: sampling, biology, population dinamics and forecasting. Revue Suisse d'Agriculture, v.27, p.345-349, 1995.

JONGJIN, L.; YOO, M.; SO, S.S. Defence mechanism of glandular trichome of Solanum tuberosum against Myzus persicae (Homoptera: Aphididae). I. Morphology of trichome and effects of its extract on development of the aphid. Korean Journal of Entomology, v.29, p.189-193, 1999.

KUROLI, G.; L. NEMETH; POCSAI, K. Effect of primary metabolites on the number of aphids. In: INTERNATIONAL SYMPOSIUM ON CROP PROTECTION, 50., 1998, Ghent. Proceedings.. Ghent: Ghent University, 1998. p.339-344.

LARA, F.M. Princípios de Resistência de Plantas a Insetos. 2. ed., São Paulo: Ícone Editora, $1991.336 \mathrm{p}$.

LARA, F.M.; SILVA, E.A.; BOIÇA JÚNIOR, A.L. Resistência de genótipos de batata, Solanum spp. a afídeos (Homoptera: Aphididae) e influência sobre parasitóides. Anais da Sociedade Entomológica do Brasil, v.28, p.721-728, 1999.

MORAES, J.C.; VILELA, E.F. Antixenose ao pulgão Myzus persicae (Sulzer), em clones da batateira silvestre Solanum berthaultii, portadores de tricomas glandulares. Anais da Sociedade Entomológica do Brasil. v.24, p.613-618, 1995.
PETITT, F.L. ; SMILOWITZ, Z. Green peach aphid feeding damage to potato in various plant growth stages. Journal of Economic Entomology, v.75, p.431-435, 1982.

RADCLIFFE, E.B. Insect pest of potato. Аnпиаl Review of Entomology, v.27, p.173-204, 1982.

RADCLIFFE, E.B.; LAUER, F.I. Resistance to green peach aphid and potato aphid in introductions of wild tuber-bearing Solanum species. Journal of Economic Entomology, v.64, p.1260-1266, 1971.

REININK, K.; DIELEMAN, F.L. Resistance in lettuce to the leaf aphids Macrosiphum euphorbiae and Uroleucon sonchi. Annals of applied Biology, v.115, p.489-498, 1989.

STEIN, C.P. Resistência de cultivares de Solanum tuberosum $e$ de híbridos de $\mathrm{S}$. tuberosum $x \mathrm{~S}$. berthaultii $a$ Myzus persicae (Sulzer), Liriomyza huidobrensis (Blanchard) e Phthorimaea operculella (Zeller) avaliada pela infestação e por danos em tubérculos. ESALQ/USP, Piracicaba, 1998. 71 p. (Tese mestrado)

TINGEY, W.M.; YENCHO, C.G. Insect resistance in potato: a decade of progress. p.405-425. In: ZEHNDER, G.W.; POWELSON, M.L.; JANSSON, R.K.; RAMAN, K.V. (Eds). Advances in potato pest biology and management. New York: APS press, 1994. 655p.

TINGEY, W.M., PLAISTED, R.L.; LAUBENGAYER, J.E.; MEHLENBACHER, S.A. Green peach aphid resistance by glandular trichomes in Solanum tuberosum x S. berthaultii hybrids. American Potato Journal, v.59, p.241251, 1982.

XIA, J.; TINGEY, W.M. Green peach aphid (Homoptera: Aphididae): developmental and reproductive biology on a resistant hybrid potato. Journal of Economic Entomology, v.79, p.71-75, 1986. 